\title{
The effects of size changes on haptic object recognition
}

\author{
Matt Craddock and Rebecca LaWson \\ University of Liverpool, Liverpool, England
}

\begin{abstract}
Two experiments examined the effects of size changes on haptic object recognition. In Experiment 1, participants named one of three exemplars (a standard-size-and-shape, different-size, or different-shape exemplar) of 36 categories of real, familiar objects. They then performed an old/new recognition task on the basis of object identity for the standard exemplars of all 36 objects. Half of the participants performed both blocks visually; the other half performed both blocks haptically. The participants were able to efficiently name unusually sized objects haptically, consistent with previous findings of good recognition of small-scale models of stimuli (Lawson, in press). However, performance was impaired for both visual and haptic old/new recognition when objects changed size or shape between blocks. In Experiment 2, participants performed a short-term haptic shapematching task using 3-D plastic models of familiar objects, and as in Experiment 1, a cost emerged for ignoring the irrelevant size change. Like its visual counterpart, haptic object recognition incurs a significant but modest cost for generalizing across size changes.
\end{abstract}

A central feature of human object recognition is the ability to recognize an object despite the wide variety of perceptual inputs that can be associated with it. Our visual system can cope with many disruptive transformations, such as changes in viewpoint, lighting, or color. We are also capable of visually recognizing objects despite variations in size (e.g., Jolicœur, 1987; Uttl, Graf, \& Siegenthaler, 2007). Two distinct aspects are involved in this capability. First is the ability to perceive physical rather than retinal size: A nearby object projects a larger retinal image than does an identically sized object that is farther away, yet we do not typically perceive the more distant object to be smaller. Thus, although retinal image size is a product of both the physical size of an object and its distance from the observer, we normally perceive an object's size to be close to its physical size. This ability is called size constancy. The second aspect is our ability to generalize recognition of objects across physical size changes; thus, we can recognize both a small and a large cup as cups. The latter ability, to generalize over physical rather than retinal size changes, is the focus of the present study. Specifically, we consider how the haptic and visual modalities compare in their abilities to generalize across physical size changes.

\section{Visual Size-Change Effects}

A considerable body of research has examined how size changes affect visual object recognition. Jolicœur (1987) reported a size-change cost in old/new recognition with line drawings of familiar objects. Participants were shown either large or small pictures of objects at study; at subsequent test, half of the shapes were shown at the same size as at study, and half were shown at the other size. Recognition was slower and less accurate when objects changed size from study to test. Biederman and Cooper (1992; see also Fiser \& Biederman, 1995) tested priming of naming and same/different matching of line drawings of familiar objects. In three experiments, participants saw these drawings twice; half were shown at the same size both times, and half were shown at different sizes. Size changes did not affect priming of naming but did impair same/different matching. Cooper, Schacter, Ballesteros, and Moore (1992) showed participants line drawings of structurally possible or impossible unfamiliar objects and found that size changes did not affect priming of structural possibility judgments, but did impair old/new recognition. Uttl et al. (2007) showed participants color photographs of common objects against a blank background; these photographs were scaled to give three different sizes of each object. Participants rated the familiarity of the objects in the photographs, and completed either a naming or an old/new recognition task immediately after the study phase and again 1 week later. Naming was not affected by size changes from study to test, and recognition was close to ceiling in the immediate test. In the delayed test, size changes impaired old/new recognition, but only when large versions of objects were seen at test.

Together, these studies suggest that size changes incur a cost for old/new recognition and matching (though not for priming) tasks. However, this cost could be due to either physical or retinal size changes, since all of these studies focused on 2-D images of isolated 3-D objects presented on a computer monitor. With no context in which to place

M. Craddock, m.craddock@liv.ac.uk 
the objects other than the monitor itself, the visual system could have interpreted size changes as due either to alterations in the 3-D physical size of an object or to variation in its distance from the observer. The latter interpretation would alter retinal size but not the perceived physical size. Milliken and Jolicœur (1992) investigated the latter possibility by manipulating participants' distance from the stimulus as well as the stimulus size. Their participants saw novel 2-D line drawings presented on a monitor and studied the small-sized shapes from a distance of $66 \mathrm{~cm}$ and the large-sized ones from $132 \mathrm{~cm}$. At test, the participants saw some objects from the same distance as during study and some from the other distance and performed an old/new recognition task. When objects were seen at the same distance, same-sized objects were the same retinal size at study and test, whereas changed-size objects were different retinal sizes at study and test. Conversely, when objects were seen at different distances, same-sized objects were different retinal sizes at study and test, whereas changed-size objects were the same retinal size at study and test. If size-change effects in recognition were due to retinal size, performance should have been better for same-sized objects in the same-distance condition but better for changed-size objects in the different-distance condition. Instead, recognition was better for same-sized objects in both conditions, indicating that physical rather than retinal size was driving size-change costs.

Bennett and Warren (2002) also attempted to dissociate retinal size from physical size. They presented randomly constructed, silhouetted statue-like stimuli placed in a checkerboard hallway on a computer screen. On each trial, two identical or two different-shaped stimuli were presented simultaneously, and the relative retinal and physical sizes of these object pairs were varied. Participants had to judge whether the two objects were the same or different shapes. Response times (RTs) increased as both retinal and physical size differences between the two objects increased. However, both of those stimuli were visible simultaneously; stored representations may be less sensitive to retinal size, so effects of physical size might dominate in a task requiring the use of memory.

Finally, people's estimates of the size of projections of objects on mirrors and windows are strongly biased toward the physical rather than the projected size of the objects (Lawson \& Bertamini, 2006; Lawson, Bertamini, $\&$ Liu, 2007). For example, people typically estimate the projected size of their own face on the surface of a mirror as being close to the actual physical size of their face, irrespective of the viewing distance. However, the surface area of a mirror projection of your own face is always half the width and height of your actual face.

\section{Haptic Versus Visual Object Recognition}

The goals of the haptic and visual object recognition systems are similar, and recent research has begun to investigate the extent to which common representations and brain regions may be involved in both systems. Behavioral studies have demonstrated both similarities and differences between haptic and visual object recognition in generalizing over orientation changes (Craddock \&
Lawson, 2008, in press; Lacey, Peters, \& Sathian, 2007; Lawson, in press; Newell, Ernst, Tjan, \& Bülthoff, 2001). In the present study, we extended this research to examine how changes in physical size affect haptic relative to visual object recognition.

Several neuroimaging studies have reported considerable overlap between the brain areas involved in haptic and visual object recognition, with the lateral occipital complex (LOC) particularly highlighted for its involvement in processing of 3-D shape (Amedi, Jacobson, Hendler, Malach, \& Zohary, 2002; Amedi, Malach, Hendler, Peled, \& Zohary, 2001; Amedi, von Kriegstein, van Atteveldt, Beauchamp, \& Naumer, 2005; Deibert, Kraut, Kremen, \& Hart, 1999; James, Humphrey, Gati, Servos, et al., 2002; James, Kim, \& Fisher, 2007; Miquée et al., 2008; Sathian \& Lacey, 2007; Zhang, Weisser, Stilla, Prather, \& Sathian, 2004). Size invariance and orientation dependence have been observed in the LOC in response to visual inputs (James, Humphrey, Gati, Menon, \& Goodale, 2002; Vuilleumier, Henson, Driver, \& Dolan, 2002), but such manipulations have yet to be systematically investigated for haptic inputs.

Some research has examined how haptic and visual perceptual information about objects is integrated. Although combined haptic and visual exploration of an object can lead to a visually dominated percept (Rock \& Victor, 1964), Ernst and Banks (2002) showed that as the reliability of visual information decreases, greater weight is attached to haptic information. Gepshtein and Banks (2003) examined visual, haptic, and combined visuohaptic estimates of the distance between two transparent planar surfaces. The accuracy of visual estimates declined when the surfaces were both perpendicular to the observer's line of sight, with the nearer surface occluding the farther, whereas haptic estimates were unaffected by the orientation of the two surfaces. Combined estimates were more accurate than either of the unimodal estimates and were also unaffected by surface orientation. Furthermore, some object characteristics are generally processed more efficiently by touch: The experiments above employed only spatial and geometric tasks, but Lederman, Thorne, and Jones (1986), for example, demonstrated that touch dominates vision in judgments of the surface roughness, as opposed to the spatial density, of raised dot patterns on a textured surface (see Lederman \& Klatzky, 2004, for a review). Thus, different factors can affect perception in each modality, and visual inputs do not necessarily dominate object perception.

There are good reasons to expect that size might influence haptic object recognition differently from visual object recognition. Distance cues and retinal size both contribute to the visually perceived size of an object (Haber \& Levin, 2001); visual estimation of physical size occurs automatically (Goldfarb \& Tzelgov, 2005) and begins in early visual cortex (Murray, Boyaci, \& Kersten, 2006). However, whereas vision combines both direct, objectspecific cues and indirect, environmental cues, haptic size is normally perceived only through direct contact. An inverse relationship between distance and perceived size has been observed when haptic perception is extended by 
means of a wooden rod (Barac-Cikoja \& Turvey, 1995). However, in most circumstances, no distance separates the hands from the object being perceived haptically. Typically, haptically perceived size depends on several factors, including the spread of the fingers on initial contact with an object and the compliance of the object's surface (Berryman, Yau, \& Hsiao, 2006). Prolonged visual experience can modulate the perceived distance between two points of contact on the skin (Taylor-Clarke, Jacobsen, \& Haggard, 2004), but such modulation is probably rare in everyday life. An object's size and shape place constraints on how it is grasped, so an accurate representation of size is important for object manipulation. The action of grasping itself is similar to enclosure, an exploratory procedure particularly associated with the haptic perception of size (Lederman \& Klatzky, 1987). However, Westwood and Goodale (2003) found that although a size-contrast illusion decreased the accuracy of haptic size estimation, grip aperture was unaffected, suggesting that a dissociation may exist between haptic size perception and grasping.

Information about physical size may be more important for haptic than for visual object recognition, since fewer alternative sources of information may be available haptically than visually. Furthermore, as compared with alternative object properties, size information may be relatively more reliable for haptics than for vision. If, relative to other cues, size information is easier to extract, is more reliable, or is weighted more highly in haptics than in vision, size changes may perturb haptic more than visual processing.

There is evidence that haptics and vision may differ in their relative weightings of different sources of information. For example, Cooke, Jäkel, Wallraven, and Bülthoff (2007) investigated the relative importance of object features such as shape and texture across haptic and visual modalities in a similarity rating study. They found that although haptics and vision use broadly similar perceptual maps for comparing stimuli, shape was much more important than texture for vision, whereas shape and texture were similarly important for haptics. In a free-sorting task, Lederman, Summers, and Klatzky (1996) found that shape was the most salient dimension for both touch and vision, and that shape was more salient for vision than for touch. Size was as rapidly available as shape for haptics, but it was not a salient dimension for either touch or vision. Similarly, Klatzky, Lederman, and Reed (1987) found evidence that size information may be given little weight by either haptics or vision. When participants were directed to sort stimuli along one of several dimensions, both haptic and visual size sorting was poor, and when freely sorting these stimuli by similarity, size was the least frequently used dimension. As was also found by Cooke et al. (2007), material qualities were more salient to touch than to vision. However, Reed, Lederman, and Klatzky (1990) found that size was weighted strongly by participants who had to learn to haptically classify a set of 2-D planar stimuli that varied in size, shape, texture, and hardness. When classes defined by two dimensions (e.g., size and shape) were learned, removing the size cue disrupted performance more than did removing any of the other three cues. Furthermore, even when exploratory proce- dures were restricted to contour following, size information was still most important, although the procedure normally used to detect size - enclosure - was not available.

Thus, some evidence has suggested the importance of size to haptic classification, but only one study, reported by Srinivas, Greene, and Easton (1997), has specifically examined the interaction between input modality and the effect of size changes on object recognition. Srinivas et al. compared memory for haptically and visually perceived 2-D novel patterns. They presented novel three-line patterns either as raised lines, in the haptic condition, or drawn on paper, in the visual condition. At study, participants described the patterns. At test, each stimulus was presented again in the same modality at either the same or a different size and orientation. Participants then either drew each stimulus or performed an old/new recognition task. Orientation changes from study to test worsened both haptic and visual drawings, whereas size changes worsened only the haptic drawings. Orientation and size changes disrupted recognition to similar extents for both the haptic and visual modalities.

The results of Srinivas et al. (1997) provided evidence for broadly similar representational strategies across the two modalities. However, the disruptive effect of size changes on haptic but not visual drawings suggests that size may be a more important factor for haptic than for visual object recognition (see also Reed et al., 1990). Both Reed et al. and Srinivas et al. used simple 2-D stimuli that lacked many of the features to which haptic perception is best attuned, and both limited the use of typical haptic exploratory procedures (Klatzky et al., 1987; Lederman \& Klatzky, 1987, 1990). Lawson (in press) showed that people are able to haptically recognize small-scale models of familiar objects quite efficiently. These models included stimuli with which people would have little or no direct haptic experience, such as canoes, submarines, and various animals. However, Lawson (in press) did not directly manipulate model size. In the present study, we tested whether size changes influence the short-term matching of small-scale models of familiar 3-D objects (Experiment 2) and the recognition of more ecologically valid everyday 3-D objects (Experiment 1).

\section{EXPERIMENT 1}

Experiment 1 compared the effects of size changes across the haptic and visual modalities using an old/new recognition task. We formulated two alternative hypotheses. First, as outlined above, and consistent with the results of the drawing task reported by Srinivas et al. (1997), size may be of greater diagnostic value to haptic than to visual object recognition. If so, size changes may disrupt haptic more than visual performance. Second, haptics and vision may both use the same rescaling processes to match different-sized exemplars of a given category to a more abstract, general representation for recognition. Thus, both modalities may display similar costs to achieve generalization over size changes.

These two hypotheses about the relative importance of size information for haptic and for visual object recogni- 
tion need to be tested by comparing haptic with visual performance on the same task. Objects must normally be within reach to be explored haptically, and they must therefore be placed within a clearly defined spatial context. In contrast, visual experiments have usually presented 2-D images of 3-D objects shown in isolation on a computer monitor, with no background and without strong cues as to their actual physical size or 3-D location (e.g., Biederman \& Cooper, 1992; Cooper et al., 1992; Fiser \& Biederman, 1995; Jolicœur, 1987; Uttl et al., 2007), or, alternatively, have presented novel 2-D objects, again with no meaningful background (Milliken \& Jolicœur, 1992; Srinivas et al., 1997). Without information about the spatial location of an object, it is impossible to distinguish between physically larger and physically closer objects. Although Bennett and Warren (2002) attempted to dissociate these processes by picturing objects within a spatial context, they did not test the size specificity of longer-term memory.

In Experiment 1, we attempted to maintain similar conditions for both modalities. Two separate groups of participants took part in the haptic and visual conditions. In the first of the two experimental blocks, participants named one of three exemplars of 36 categories of familiar objects: a standard, a different-sized but similarly shaped, or a different-shaped but similarly sized exemplar. In the second block, participants performed an old/new recognition task on the standard exemplars of the same 36 familiar objects, intermingled with 25 new familiar objects. They were told to disregard any physical changes in the objects and to base their decisions on the objects' names.

We presented different-shape exemplars to test the possibility that minor shape changes may cause differences in performance observed on size-change trials. Real objects were used in Experiment 1, so there were usually minor shape changes between the different-size exemplars (e.g., between a large and a small cup) in addition to the size change. The different-shape exemplars were chosen to be similar in size to the standard objects but to have different shapes (see Figure 1). If any effects of size changes are caused by minor shape changes, the shape-change trials should elicit much larger costs on performance than do the size-change trials. However, if size changes per se influence object recognition, size-change trials should produce a cost to recognition at least as large as the cost on shapechange trials.
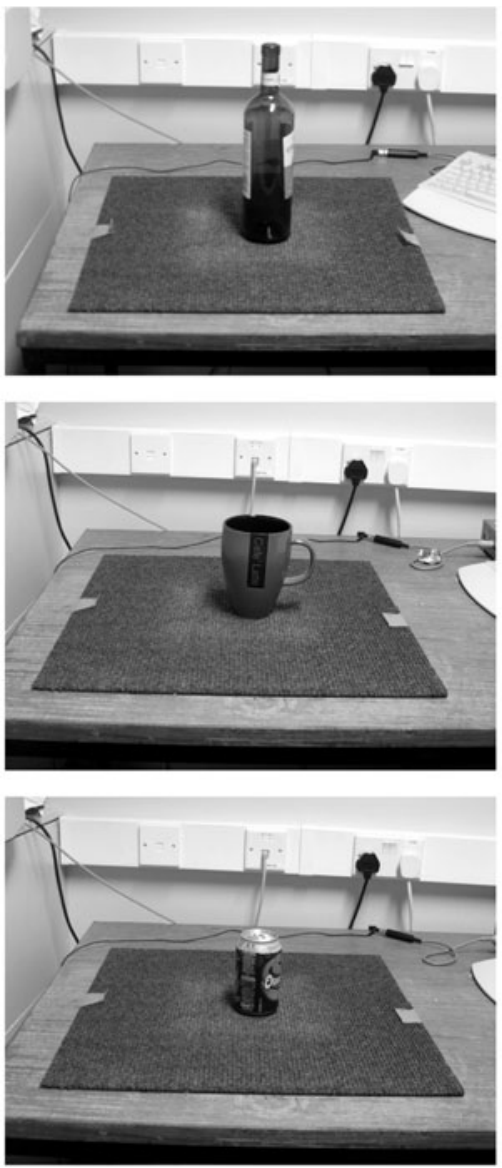
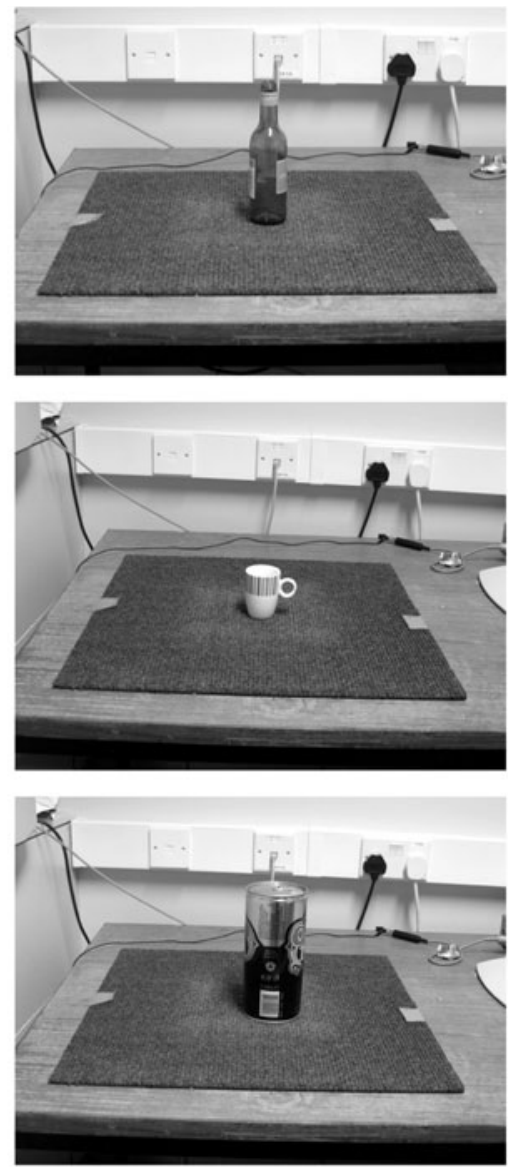
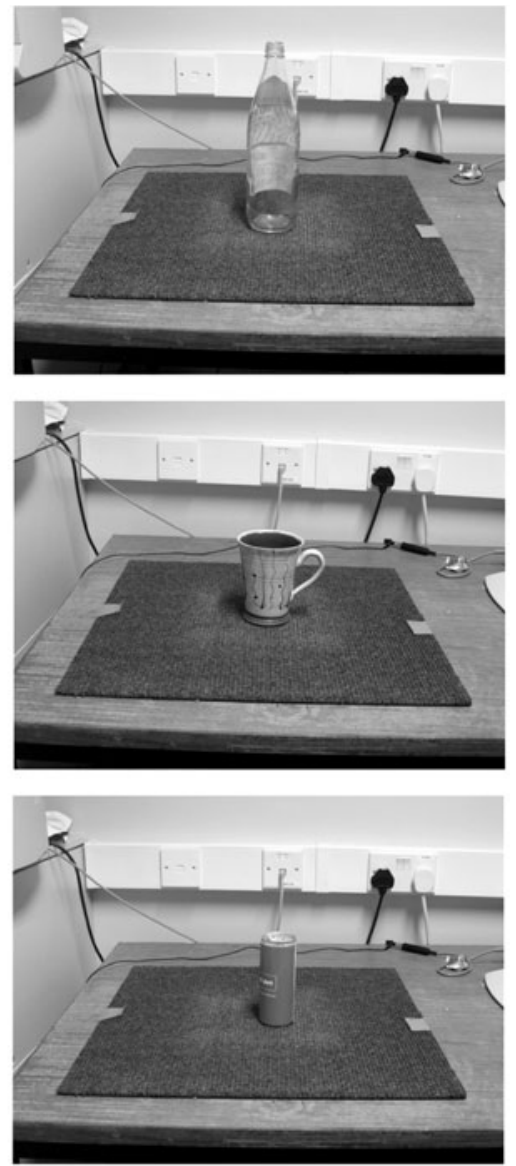

Figure 1. Three of the old objects (bottle, cup, and can) presented as 3-D stimuli in the haptic condition, in the same context depicted in these photographs, and as the photographs shown here in the visual condition. In each row, photographs from left to right show the standard, different-size, and different-shape exemplars. The direction and magnitude of the size change varied across items; here, the different-size bottle and cup are smaller than the standard exemplar, whereas the different-size can is larger. 
In the haptic condition, real, 3-D objects were presented to blindfolded participants. In the visual condition, grayscale 2-D photographs of the same objects were presented on a computer screen. These photographs depicted the objects in the same location in which they were presented in the haptic condition and from a height and angle approximately on the same line of sight as for the observers in the haptic condition (see Figure 1). Thus, unlike previous visual size-change experiments, visual objects were presented within a well-specified and constant 3-D spatial context that contained many cues as to their physical size. In particular, it was clear that different-sized objects were presented in the size-change condition rather than the same objects at a different distance. The visual version of our task thus extended Milliken and Jolicœur's (1992) test for the effects of size changes in which distance could not be a confounding factor.

\section{Method}

\section{Participants}

Sixty right-handed students from the University of Liverpool participated in return for course credit. Handedness was self-reported, and their ages ranged from 18 to 36 years. Thirty participants took part in the haptic condition, and 30 in the visual condition.

\section{Stimuli}

Sixty-one familiar categories of objects were presented either haptically or visually, in the haptic or visual condition, respectively. Three exemplars of 36 of these object categories were used as the old objects (see Figure 1). One exemplar had a standard size and shape (standard), another had a different size from the standard but a similar shape (different size), and the third had a similar size to the standard but a different shape (different shape). Each standard exemplar had a typical size and shape for an exemplar of that category.

We verified the selection of these exemplars using a set of visual rating studies. Twenty undergraduate students at the University of Liverpool (age, 18-20 years) who did not take part in the other experiments rated photographs of each of the three exemplars of the 36 old-object categories on a scale from 1 (low) to 7 (high) for typicality - in all cases - and for similarity of the different-size and different-shape exemplars to the standard exemplars. All of these participants rated the typicality of all three exemplars of each object, and the standard exemplars were rated as more typical (5.3) than either the different-size (4.9) or the different-shape (4.8) exemplars. Ten of these rating participants were then shown pairs of photographs and rated the exemplar pairs for similarity. For each object category, they were shown the standard exemplar twice, paired once with the different-size exemplar and once with the differentshape exemplar. Different-size exemplars (4.7) were rated as more similar to the standard exemplars than were the different-shape exemplars (4.2). The other 10 rating participants were shown trios of photographs of each object category and chose which, between the different-size and different-shape exemplars, was most similar to the standard exemplar. Participants chose the different-size exemplar as more similar on $66 \%$ of trials. These rating studies thus supported the classifications of the object exemplars (see also Appendix A).

The remaining 25 objects were used as new objects and were standard-size-and-shape exemplars of their category (see Appendix B). Five additional objects were used as practice items.

In the haptic condition, the actual objects were presented. In the visual condition, grayscale photographs of the objects were presented. These photographs depicted the objects in the same experimental context, location, and position in which they were presented in the haptic condition. Color was removed, since that could have provided a visual cue to recognition that was not available for haptics. All photographs were taken from a fixed distance of ap- proximately $1 \mathrm{~m}$ and a fixed angle approximately along the line of sight of the observers in the haptic condition. Participants were seated approximately $60 \mathrm{~cm}$ from the 17 -in. monitor on which the photographs were presented. The full photographs all subtended a visual angle of $18^{\circ} \times 23^{\circ}$. The average visual angles of the objects shown in the photographs were quite similar across the three types of exemplar, around $3^{\circ} \times 3^{\circ}$. The average difference in visual angle between the standard exemplars and the different-size exemplars was $\pm 1.5^{\circ} \times \pm 1.5^{\circ}$, whereas the difference between the standard exemplars and the different-shape exemplars was $\pm 0.4^{\circ} \times \pm 0.6^{\circ}$. Thus, the visual angle of the different-size exemplars differed more from that of the standard exemplars than did the visual angle of the different-shape exemplars.

\section{Design and Procedure}

The haptic and visual participants were allocated to three subgroups, and the old objects were divided into three sets of 12 items. In the first, naming block, each subgroup was presented with the standard exemplars from one set, the different-size exemplars from another set, and the different-shape exemplars from the final set. The sets allocated to each subgroup at study were counterbalanced using a Latin-square design. Standard exemplars of all of the old and the new objects were presented in the second, recognition block.

All participants first read a list of the names of the experimental objects. In the haptic condition, participants were then shown the $50-\mathrm{cm}^{2}$ carpet tile on which the objects would be placed and the starting positions in which they should place their hands. These positions were indicated by pieces of masking tape at the center of the left and right edges of the carpet tile (see Figure 1). The tape allowed participants to locate the starting hand positions consistently without vision. A carpet tile was used to muffle any sounds made by placing the objects. Participants then put on a pair of safety goggles covered in masking tape and confirmed that they were unable to see the area in which the objects would be placed.

All participants were given five practice trials in which they named objects. They then completed the study block of 36 naming trials and the test block of $61 \mathrm{old} / \mathrm{new}$ recognition trials. Participants were given a brief break between the two experimental blocks and were not informed that objects would be repeated during the second block. During the break in the haptic condition, the objects were hidden, and participants were allowed to remove their goggles.

In the haptic condition, the experimental software package PsyScope 1.2.5 (Cohen, MacWhinney, Flatt, \& Provost, 1993) generated the order of presentation of the objects and was used to record responses. In the first block, objects were presented in a random order. In the second block, objects were presented in a pseudorandomly determined order. The order of trials in the first block was randomized for each participant, but the order of trials in the second block was the same for all participants. On each trial, the experimenter placed an object in the center of the carpet tile, at a fixed orientation in depth, and started each trial once a participant had positioned both hands on the tape markers. A single, low-pitched warning beep was played, followed by a high-pitched double beep $1 \mathrm{sec}$ later to indicate that participants could start to move their hands to touch the object. Single, low-pitched beeps then occurred every second for the next $3 \mathrm{sec}$, followed by a high-pitched double beep $4 \mathrm{sec}$ after the starting double beep. This second double beep indicated that participants should stop touching the object and return their hands to the starting positions. Participants were informed that they should use both hands to explore the object freely and that they were allowed to lift it.

In both blocks, participants were given up to $4 \mathrm{sec}$ to haptically explore each object, and trials ended only when they had made a response. Trials on which they responded after the final double beep were not classed as errors. In the first block, participants were instructed to name the objects both quickly and accurately, ceasing exploration as soon as they had named the object or the second double beep had sounded. In the second block, they had to state whether each object was "old"-previously studied-or "new"- unstudied. They were instructed to decide on the basis of object identity and to 
ignore any size or shape changes in the objects. RTs were recorded using a microphone headset attached to a Macintosh computer that acted as a voice key. The experimenter recorded incorrect responses, trials on which the microphone was activated before the participant responded (voice-key errors), and trials on which the participants started to move before the starting beep (movement errors). No feedback on accuracy was provided.

In the visual condition, the experimental software package E-Prime 2.0 (Psychology Software Tools, Inc., Pittsburgh, PA) was used to generate the order of presentation and to record RTs. As in the haptic condition, the objects were presented in a random order in the first block and in a fixed, pseudorandomly determined order in the second block. On each trial, participants heard a single beep, then a double beep. The photographs appeared in the center of the screen when the double beep sounded and disappeared when a participant responded. Unlike in the haptic trials, there was no fixed presentation time, since visual naming is typically much faster than haptic naming. RTs were recorded using a microphone connected to a Windows PC via an E-Prime response box. The experimenter recorded incorrect responses and voice-key errors. No feedback on accuracy was provided.

\section{Results}

The results were analyzed using mixed ANOVAs conducted on median correct RTs and percentage errors in by-participants $\left(F_{\mathrm{p}}\right)$ and by-items $\left(F_{\mathrm{i}}\right)$ analyses for naming responses in Block 1 and old/new recognition memory in Block 2. Study exemplar (standard, different-size, or different-shape) was used as a within-participants/-items factor. Subgroup (which set of old items was assigned to each study exemplar condition) was used as a betweenparticipants factor, and object set was used as a betweenitems factor. Effects involving the latter two counterbalancing factors were not of theoretical interest, and so are not reported.

It would have been interesting to compare the two conditions directly, using modality as a between-participants factor. However, the variances of the visual RTs were much lower than those of the haptic RTs, which led to a violation of the assumption of homogeneity of variances and to a consequent loss of statistical power. Normalizing the RT distributions using procedures such as logarithmic or inverse transformations did not solve this problem. Thus, we analyzed the results from the haptic and visual conditions separately. The above assumption was not violated for errors, but, since the interaction between exemplar and modality was not significant for errors, we report both RT and error analyses separately for each modality for ease of interpretation.

Trials were excluded from the RT analyses if voice-key errors (haptic Block 1, 6\%; haptic Block 2, 2\%; visual Block 1, 8\%; visual Block 2, 4\%), movement errors (haptic only, $1 \%$ in both blocks), or naming errors in Block 1 (haptic, 9\%; visual, 5\%) occurred. Trials on which voicekey, movement, or naming errors occurred in Block 1 were also excluded from the RT analyses in Block 2, and vice versa. Haptic RTs below $750 \mathrm{msec}$ or exceeding $10,000 \mathrm{msec}$ were discarded as errors (less than $1 \%$ of trials), as well as visual RTs below $375 \mathrm{msec}$ or exceeding 5,000 msec (less than $1 \%$ of trials). Both cutoffs applied to both blocks. Note that there was overlap between the error types classified above: For example, both voice-key and naming errors occurred on some trials. Altogether, $12 \%$ of trials were excluded under these criteria from both the haptic and visual analyses.

Three participants in the haptic condition were replaced because they committed voice-key errors on over $18 \%$ of trials. No participants were replaced in the visual condition. All results are reported as significant at $p<.05$. Bonferroni correction for multiple comparisons was used on all post hoc pairwise comparisons. Tukey's HSD tests were conducted on significant interactions. There was no indication of a speed-accuracy trade-off in any condition.

\section{Block 1}

Haptic naming. There was no effect of study exemplar on either naming RTs $\left[F_{\mathrm{p}}(2,54)=2.291, p=.1 ; F_{\mathrm{i}}(2,66)=\right.$ $2.270, p=.1]$ or errors $\left[F_{\mathrm{p}}(2,54)=2.024, p=.1 ; F_{\mathrm{i}}(2,66)=\right.$ $0.798, p=.5]$. Standard ( $2,952 \mathrm{msec}, 8 \%$ errors), differentsize (3,081 msec, $12 \%)$, and different-shape (3,084 msec, $9 \%$ ) exemplars were all named similarly quickly and accurately, but there was a trend for different-size and different-shape objects to be named more slowly - by 129 and $132 \mathrm{msec}$, respectively - than the standard objects.

Visual naming. A significant effect of study exemplar emerged on naming RTs for participants only $\left[F_{\mathrm{p}}(2,54)=5.438, p=.007 ; F_{\mathrm{i}}(2,66)=2.194, p=.1\right]$, but not on errors $\left[F_{\mathrm{p}}(2,54)=0.258, p>.8 ; F_{\mathrm{i}}(2,66)=\right.$ $0.333, p>$.7]. Different-size $(1,039 \mathrm{msec}, 5 \%$ errors $)$ and different-shape (1,034 msec, $5 \%)$ exemplars were named more slowly - by 76 and $71 \mathrm{msec}$, respectively - than the standard exemplars (963 msec, 6\%), although only the difference between different-size and standard exemplars was significant in post hoc by-participants comparisons. The pattern of performance was similar to that observed in the haptic condition.

\section{Block 2}

Haptic old/new recognition. There was a significant effect of study exemplar for both RTs $\left[F_{\mathrm{p}}(2,54)=\right.$ $\left.16.411, p<.001 ; F_{\mathrm{i}}(2,66)=16.123, p<.001\right]$ and errors $\left[F_{\mathrm{p}}(2,54)=5.729, p=.006 ; F_{\mathrm{i}}(2,66)=6.092, p=.004\right]$ see Figure 2. Post hoc comparisons revealed that objects that had been studied at a different size $(2,941 \mathrm{msec}, 7 \%$ errors) or with a different shape $(2,869 \mathrm{msec}, 7 \%)$ were recognized more slowly and less accurately—by $295 \mathrm{msec}$ and 5\% and by $223 \mathrm{msec}$ and 5\%, respectively - than objects that had both the same size and shape at study and test $(2,646 \mathrm{msec}, 2 \%)$. No difference in performance emerged between exemplars studied at different sizes and with different shapes. Since only standard exemplars were presented at test, all differences were due to differences in the study exemplars. New objects $(3,184 \mathrm{msec}, 6 \%)$ were not included in the main analysis.

Visual old/new recognition. There was a significant effect of study exemplar for both RTs $\left[F_{\mathrm{p}}(2,54)=\right.$ $\left.13.019, p<.001 ; F_{\mathrm{i}}(2,66)=13.646, p<.001\right]$ and errors $\left[F_{\mathrm{p}}(2,54)=10.091, p<.001 ; F_{\mathrm{i}}(2,66)=6.781, p=\right.$ .002 - see Figure 2. Post hoc comparisons revealed that objects that had been studied at a different size $(1,128 \mathrm{msec}$, $9 \%$ errors) or with a different shape $(1,131 \mathrm{msec}, 11 \%)$ were recognized more slowly and less accurately - by 


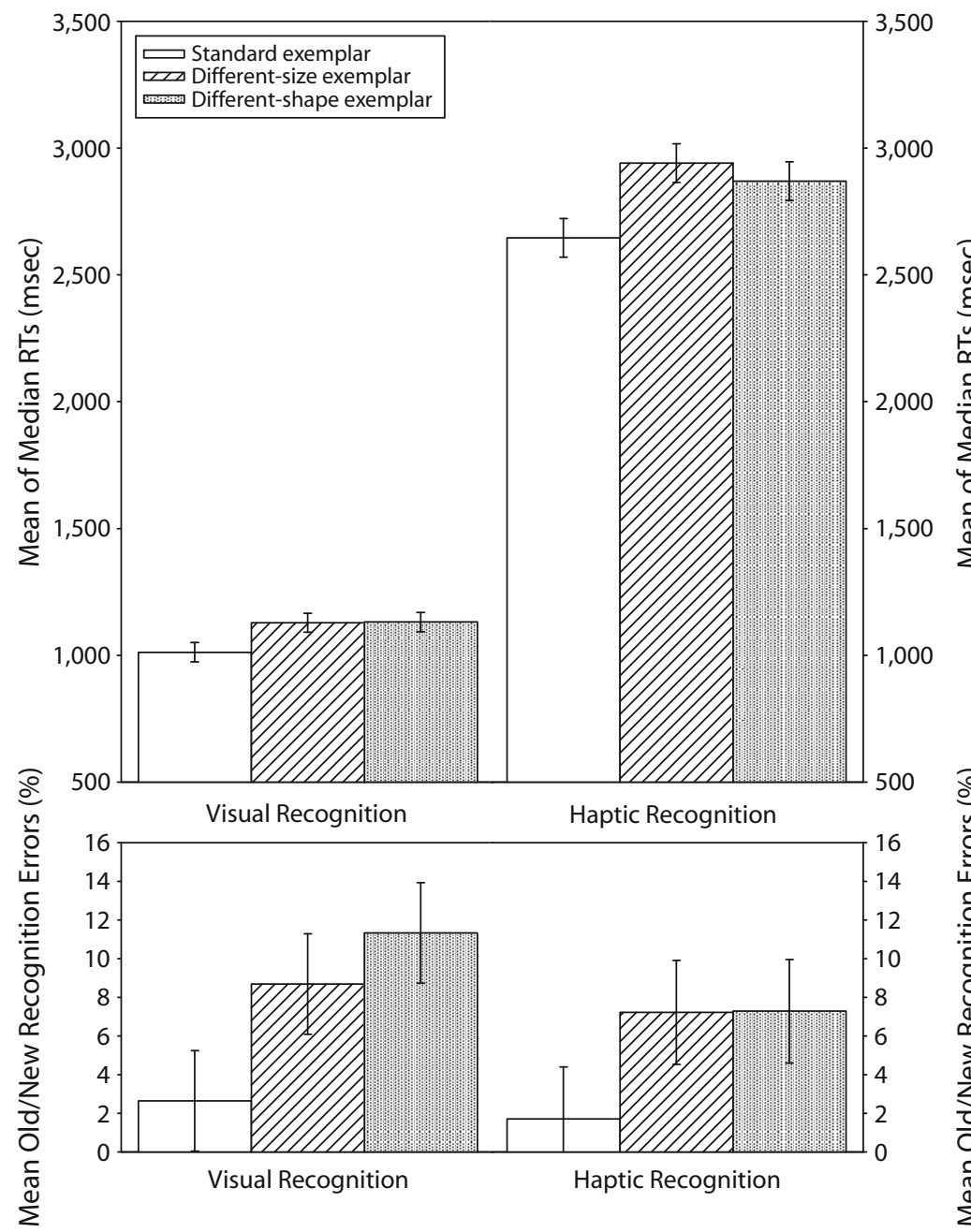

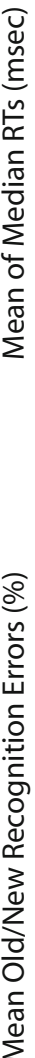

Figure 2. Mean of median old/new recognition task response times (RTs, upper graph) and percentage errors (lower graph) for the visual and haptic conditions. Error bars depict 95\% within-participants confidence intervals (Loftus \& Masson, 1994).

$116 \mathrm{msec}$ and $6 \%$ and by $119 \mathrm{msec}$ and $8 \%$, respectivelythan objects that had both the same size and shape at study and test $(1,012 \mathrm{msec}, 3 \%)$. No difference in performance emerged between exemplars studied at different sizes and with different shapes. Since only standard exemplars were presented at test, all differences were due to differences in the study exemplars. New objects $(1,157 \mathrm{msec}, 10 \%)$ were not included in the main analysis.

Amount and direction of size change, shape similarity, and their effects on recognition. We also examined the relationship between the amount of size change, the ratings of shape similarity, and Block 2 old/new recognition performance. We averaged the height, width, and length of each object to obtain an estimate of its size. For each category of old objects, we then divided the size estimates for the different-size and the different-shape exemplars by the size estimate of the standard exemplar and multiplied this proportion by 100 . This provided an estimate of the size of these exemplars as a percentage of the size of the standard exemplar. A different-size exemplar that was smaller than its standard exemplar (such as for the bottle) had a relative size estimate that was less than $100 \%$, whereas a different-size exemplar that was larger (such as for the can) had a relative size estimate greater than $100 \%$. The size change relative to the standard was simply calculated as the difference from $100 \%$, so that if the relative size of a different-shape exemplar was $90 \%$ of the standard exemplar, the estimated size change relative to the standard was $10 \%$. On this estimate, the size change relative to the standard for the different-size exemplars (on average, $\pm 45 \%$ ) was much greater than that for the different-shape exemplars $( \pm 13 \%)$. Figure 3 shows a histogram of the distributions of the estimated size changes for the different-size and different-shape exemplars. Note that most of the different-size exemplars were smaller than the standard exemplars.

We then correlated the estimated size changes, ratings of similarity, and old/new recognition RTs and errors for each category of object. For the latter two measures (RTs and errors), we subtracted performance on standard- 


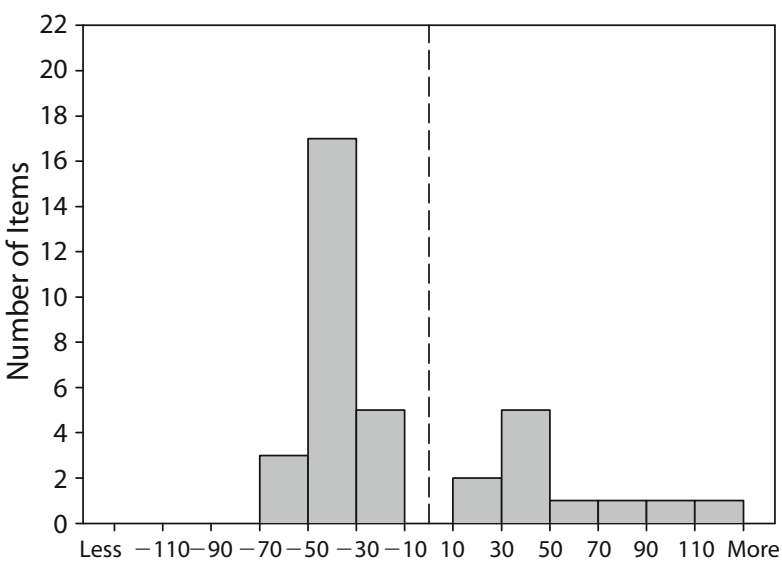

Estimated Size Change (\%) of Different-Size Exemplars

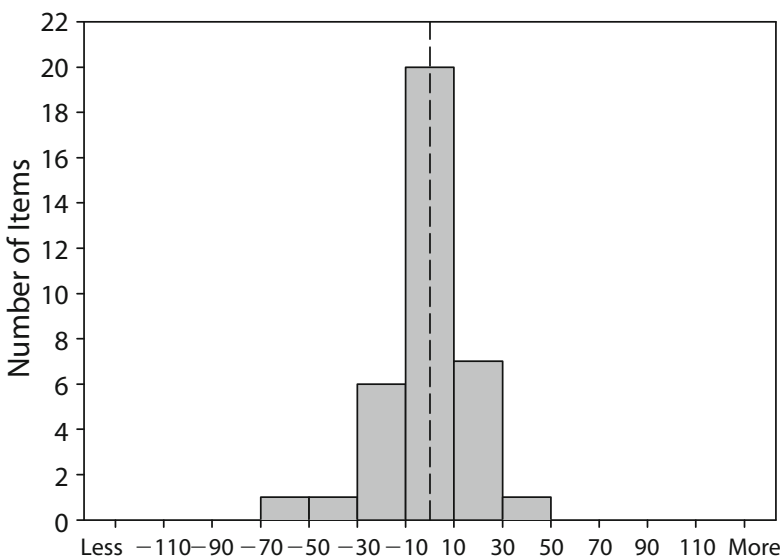

Estimated Size Change (\%) of Different-Shape Exemplars

Figure 3. Frequency histograms (bin size $=20$ ) depicting the amounts by which the different-size exemplars (top panel) and different-shape exemplars (bottom panel) differed in size from the standard exemplars. The dashed line in each panel represents zero.

exemplar trials from performance on the different-size and different-shape trials to yield a measure of the amount of disruption caused by a change in size or shape, respectively. For these analyses, if the estimated size change was negative (i.e., if the different-size or -shape exemplar was smaller than the standard exemplar), the sign of the size estimate was reversed.

In the haptic condition, there was a significant correlation between estimated size change and RTs in the different-shape condition $(r=.36, p=.03)$, and a consistent trend in the different-size condition $(r=.28$, $p<.1$ ). There were also significant correlations between estimated size change and errors in the different-shape $(r=.35, p=.04)$ and different-size $(r=.46, p=.006)$ conditions. Thus, in the haptic condition, RTs and errors both increased as the estimated size change increased for both different-shape and different-size exemplars. Shape similarity ratings for the different-size and different-shape exemplars did not correlate with RTs, errors, or estimated size changes. No significant correlations were observed in the visual condition.

\section{Discussion}

In both the haptic and visual conditions, recognition was faster and more accurate when the object was the same size and shape in both blocks than when it changed in either size or shape. Naming speeds and accuracies in Block 1 were similar for all exemplar types. Only standard exemplars were presented in Block 2, and the Block 2 analyses only included data from objects that were correctly named in Block 1 . Thus, the differences we observed cannot be due to differences in identification of the exemplars. Our finding of a cost for generalizing over size changes in both haptic and visual recognition of familiar 3-D objects replicates and extends Srinivas et al.'s (1997) finding of a cost for size changes during haptic and visual recognition of simple 2-D novel patterns. The results from our visual condition replicate previous findings of impaired old/new visual object recognition following a size change (Biederman \& Cooper, 1992; Fiser \& Biederman, 1995; Jolicœur, 1987; Uttl et al., 2007) and extend them to images of real 3-D objects placed within a rich environmental context. We will consider these results further in the General Discussion.

Both the patterns of RTs and errors and the actual error rates were similar across the two modalities. These data do not support the prediction that size changes should disrupt haptic recognition much more than visual recognition. Instead, comparable costs occurred for both modalities, despite the striking differences in how information about size is acquired in each of them. Furthermore, the costs of haptic size changes were modest in comparison with, for example, the costs to haptic recognition of removing depth information or restricting exploration (Klatzky, Loomis, Lederman, Wake, \& Fujita, 1993; Lawson, 2008; Loomis, Klatzky, \& Lederman, 1991). Our results therefore suggest that both visual and haptic forms of object recognition cope with size changes quite efficiently.

Shape changes here caused similar disruptions of old/ new recognition memory. This suggests that the perceptual representations formed during the experiment were both size- and shape-specific, since different-size exemplars were largely the same shape as standard exemplars, whereas different-shape exemplars were of largely the same size as standard exemplars. Given our use of real objects, it was not possible to fully unconfound the causal roles of size and shape changes in the present data. Our correlational analyses indicate that size changes may have been a more important modulating factor than shape changes for haptic recognition: Significant correlations were only observed for estimated size changes, not for ratings of shape similarity, and significant correlations occurred between estimated size change and both the speed and accuracy of recognition following a shape change. Thus, some of the cost of recognizing objects haptically in the different-shape condition may have been caused by size rather than shape changes.

Our measure of size change in Experiment 1 was only an approximation, and the amount and direction of size change varied across items. Experiment 2 was con- 
ducted to investigate the effects of size changes more systematically, by using pairs of custom-made objects that were identical except for a $75 \%$ size change. These stimuli allowed us to manipulate size independently of shape changes. In addition, the haptic condition in Experiment 1 took around $30 \mathrm{~min}$ to complete $-15 \mathrm{~min}$ per block - so perceptual information had to be retained over several minutes. There is evidence that haptic memory of objects alters over time, with some findings suggesting that it decays rapidly, over several seconds (e.g., Kiphart, Hughes, Simmons, \& Cross, 1992), but other research suggesting that haptic discrimination and matching may improve over time (Norman, Clayton, Norman, \& Crabtree, 2008; Zuidhoek, Kappers, van der Lubbe, $\&$ Postma, 2003). The significant recognition advantage when the standard exemplars were presented twice in Experiment 1 demonstrates that durable representations were encoded, but size changes might impair performance more on a short-term matching task than on a longer-term recognition task.

\section{EXPERIMENT 2}

In Experiment 2, participants performed a haptic sequential matching task using plastic 3-D models of familiar objects. These stimuli allowed people to use the typical hand movements associated with haptic exploration (Lederman \& Klatzky, 1987) while removing all nonshape cues to object identity. In the absence of size-invariant cues to identity, such as texture, we might expect size effects to be greater. Furthermore, a shorter-term memory task might rely more on perceptual and less on semantic and name representations than a longer-term task, which might also lead to larger size effects.

Participants haptically studied an object that was one of two sizes for $5 \mathrm{sec}$. They were then presented with either the same object on match trials or a differentshaped object on mismatch trials. This second object could be the same size as the first object or a different size. The task was to detect shape changes and to ignore size changes. On both match and mismatch trials, half of the second objects were the same size as the first object, a quarter of the objects were larger, and another quarter were smaller.

\section{Method}

\section{Participants}

Twenty-four undergraduate students from the University of Liverpool (age, 18-23 years) participated in the study for course credit. All were right-handed except for 1, who was left-handed. Handedness was self-reported.

\section{Materials and Apparatus}

The stimuli comprised two versions of a start-point morph and two versions of an end-point morph, for each of 20 morph sets of familiar objects (see Lawson, in press, for further details). The start-point and end-point morphs were similarly shaped objects that would normally be given different names-for example, sink-bath, bed-chair, and horse-giraffe. The two versions of each morph were identical, except that the small-size version had $75 \%$ of the width, height, and depth (and so, $42 \%$ of the volume) of the large-size version. Note that for the majority of objects, even the large-size version was considerably smaller than real-life exemplars of the object, since all of the morphs could be comfortably grasped by one hand. All 80 stimuli $(2$ sizes $\times 2$ morphs $\times 20$ morph sets) were $3-\mathrm{D}$, white, rigid plastic shapes printed using a Dimension 3D ABS-plastic printer (Dimension, Inc., Eden Prairie, $\mathrm{MN}$; see Figure 4).

Each morph was glued upright onto a 10-cm-square base made of carpet tile. Yellow tape marked the middle of one side of this base; the object was oriented so that its front was next to the yellow tape. The experimenter positioned objects by placing the base within a 10.5-cm-square hole cut into a surround made of a large carpet tile. One side of this hole was marked with green tape, and the yellow tape at the front of each object was always lined up with the green tape. See Lawson (in press) for photographs of the apparatus.

The object was hidden from the participant's view by a card, a board, and a clouded glass screen. Behind and perpendicular to this glass screen was a $12-\mathrm{cm}$-square aperture through which the participant's right hand entered to touch the object. Across this slot shone an infrared beam, placed so that it was broken when the participant's hand entered the slot. When the beam was broken, a detector sent a signal to the computer controlling the experiment. The participants were not allowed to move or lift the objects. Participants responded using a buttonbox placed on the table next to their left hand, in front of the glass screen. In Experiment 1, haptic exploration had involved both hands, whereas only the right hand was used in Experiment 2. However, we have found little difference between unimanual and bimanual haptic recognition, and no difference between using the dominant and the nondominant hand (Craddock \& Lawson, in
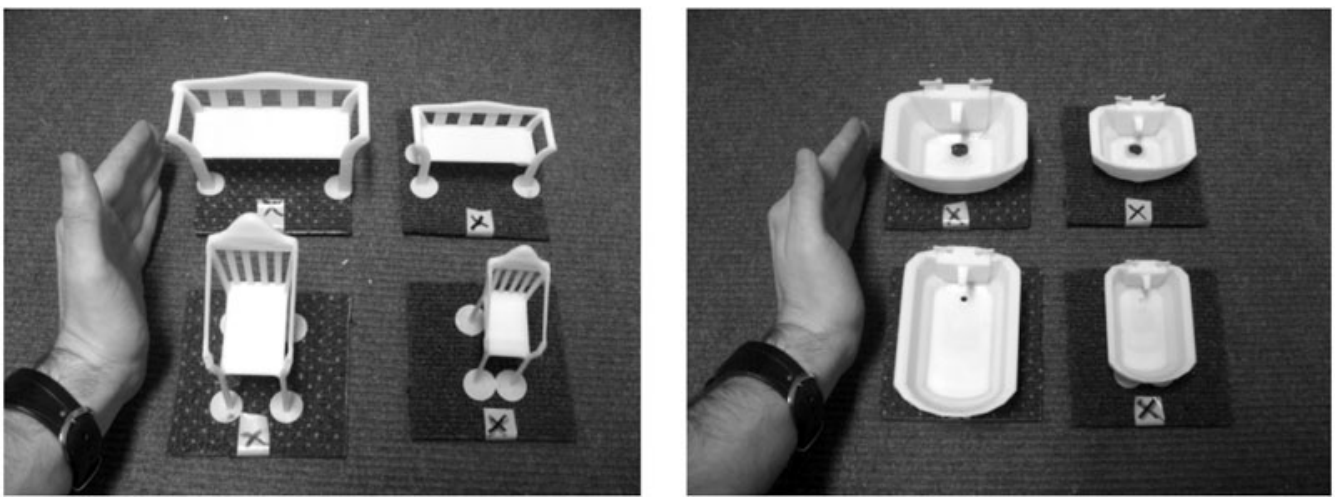

Figure 4. Examples of two sets (bench-chair and sink-bath) of morph stimuli. Each photograph shows the large exemplars on the left and the small exemplars on the right. 
press), so we did not expect this change to have much influence on performance.

\section{Design and Procedure}

All participants completed one block of 80 trials, comprising four subblocks of 20 trials. In each subblock, one morph from each of the 20 sets was presented once as the first object in a trial, and the first object alternated on each trial between a large and a small object. The full block of 80 trials contained 2 match trials and 2 mismatch trials for each morph set; on 1 of each of these 2 trials, both objects were presented at the same size, and on the other, the objects were different sizes, with the second object either larger or smaller than the first. On the 2 mismatch trials in a given condition, the same distractor morph was presented (once in a smaller and once in a larger version) as the second object.

One group of 10 morph sets was presented on 40 of the trials in a block. For these trials, the first object presented was the startpoint morph (e.g., a bath). On matches, the second object presented was the same start-point morph. On mismatches, the second object was the end-point morph from the same set (e.g., a sink). Similar conditions were run for the second group of 10 morph sets, which were presented on the remaining 40 trials. However, on these trials, the first object presented was the end-point morph (e.g., a dog). On matches, the second object presented was the same end-point morph. On mismatches, the second object was the start-point morph from the same set (e.g., a pig). Note that this design ensured that the matching task was quite difficult, since only objects with related (though readily discriminable) shapes, such as a bench and a chair, were presented on mismatch trials.

The morph sets allocated to each of the two morph groups (either start-point first or end-point first) were counterbalanced across two groups of 12 participants. Thus, one group of participants received the start-point morphs from one group of morph sets and the endpoint morphs from the other group of morph sets as the first object on a trial, and the other group received the reverse arrangement. For 6 in each group of 12 people, if the first object on a trial was a morph from the first group of morph sets, the large version was presented, and if the first object was from the second group, the small version was presented. The other 6 people had the reverse allocation of size to morph sets. In each subgroup of 6 people, 3 were given trials from the 20 morph sets in one fixed order within each subblock (e.g., with the bottle-watering can morph set presented on the first trial), and the other 3 were given the same trials in the opposite fixed order (e.g., with the bottle-watering can presented on the last trial).

The experiment was run on a computer using E-Prime (version 1.1) experimental presentation software (Psychology Software Tools, Inc., Pittsburgh, PA). At the start of each trial, the experimenter placed the first object into position behind the screen and triggered the computer to play the words "go now." This signaled to the participants that they could start to move their right hand through the aperture to touch the object behind the screen. The computer recorded when the hand broke the infrared beam across the slot. Five seconds after the beam was broken, the words "stop now" were played by the computer, signaling that participants should withdraw their hand from the slot. The experimenter then removed the first object and either put the same object behind the screen (on match trials) or replaced it with a different object (on mismatch trials). The experimenter triggered the computer to repeat the words "go now," and the participants put their hand back through the aperture to touch the second object.

Participants decided whether the two successively presented objects had the same shape and responded via a speeded keypress with the left hand. Each participant responded by pressing one of two buttons (marked same and different) on a response buttonbox, and the computer recorded the time from when the right hand had broken the infrared beam to this response. Participants were instructed to ignore any difference in size between the first and second objects and were also warned that on mismatches, the two objects might have very similar shapes. After participants had responded, they heard either a high or a low double tone as feedback, indicating either a correct or an incorrect response, respectively. They completed a block of 10 practice trials, which were identical to the final 10 experimental trials, prior to starting the experimental block.

After the first object had been presented, it was always removed from the haptic apparatus. A second object (the distractor, on mismatches, or an object from the same morph set as the first object, on matches) was then taken from the storage shelf and placed next to the first object. Finally, one of these two objects was put into the apparatus as the second object on the trial. This procedure ensured that participants could not determine from the movements of the experimenter whether they were going to be given a match or a mismatch trial. To confirm this, at the end of the study, participants were asked whether they had used only haptic information to make their responses or had also used auditory or visual information, such as sounds of the experimenter moving objects, or sight of the objects themselves. All participants said that they had used only haptic information.

\section{Results}

ANOVAs were conducted on the mean correct RTs and the percentage errors for matches and mismatches separately. On matches, same-shape responses were correct. On mismatches, shape-change responses were correct. Outlier RTs below $750 \mathrm{msec}$ or exceeding $10,000 \mathrm{msec}$ were discarded as errors (less than $1 \%$ of trials). No participants were replaced.

We analyzed one within-participants factor (size change: no change or change), as well as two counterbalancing factors: the within-participants factor of morph group (whether the first object on a trial was a start-point morph from the first group of morph sets and an endpoint morph from the second group of morph sets, or vice versa) and the between-participants factor of size group (whether a large version from the first group of morph sets was used as the first object on a trial and a small version from the second group of morph sets, or vice versa). These counterbalancing factors were not of theoretical interest, so effects involving them are not reported.

\section{Same-Shape Matches}

The effect of size change was significant for both RTs $\left[F_{\mathrm{p}}(1,22)=7.53, p<.02 ; F_{\mathrm{i}}(1,18)=7.99, p<.02\right]$ and errors $\left[F_{\mathrm{p}}(1,22)=19.64, p<.001 ; F_{\mathrm{i}}(1,18)=44.60, p<\right.$ $.001]$. Same-size matches $(2,916 \mathrm{msec}, 8.5 \%$ errors $)$ were $170 \mathrm{msec}$ faster and $13 \%$ more accurate than size-change matches (3,086 msec, $21.7 \%)$.

\section{Shape-Change Mismatches}

Here, the effect of size change was not significant for RTs $\left[F_{\mathrm{p}}(1,22)=0.31, p>.5 ; F_{\mathrm{i}}(1,18)=0.48, p>.4\right]$ or for errors $\left[F_{\mathrm{p}}(1,22)=2.96, p>.09 ; F_{\mathrm{i}}(1,18)=2.39\right.$, $p>.1]$. Responses to same-size mismatches $(2,976 \mathrm{msec}$, $25 \%$ errors) were similar to responses to size-change mismatches $(2,943 \mathrm{msec}, 20 \%)$.

\section{Comparison of the Costs of Size Changes and Orientation Changes}

An additional analysis compared the cost of size changes in the present Experiment 2 with the reliable cost of orientation changes observed by Lawson (in press) in a study that used the same sequential shape-matching task and many of the same stimuli. By-participants ANOVAs were conducted on mean correct RTs and percentage 
errors on match trials only. This analysis repeated the analysis performed above, with the addition of change type (size or orientation) as a between-participants factor. There was no interaction between change type and change (no change or change, of either type) for either RTs $[F(1,36)=2.774, p=.1]$ or errors $[F(1,36)=$ $1.181, p=.4$ ], although there was a marginal trend for RTs to be slowed more by a size change than by an orientation change. Thus, the costs were similar for a size change (viz., a $25 \%$ decrease in dimensions from large to small, or a $33 \%$ increase from small to large) and for a $90^{\circ}$ depth rotation (see Figure 5).

\section{Discussion}

Consistent with the results of Experiment 1 and of Srinivas et al. (1997), we found a clear cost of haptic size changes in Experiment 2. Experiment 2 demonstrates that the cost to haptics of ignoring size changes was not specific to either the task or the stimulus set used in Experiment 1. This supports our claim that this cost was due to the formation of a size-specific perceptual representation rather than to a shape change. However, it is important to note that this cost was as modest in Experiment 2 as in Experiment 1: Performance on size-change matches was still quite fast and accurate. In contrast to Experiment 1, in which size-invariant cues such as texture might have weakened the effects of size changes, the stimuli in Experiment 2 forced reliance on shape information. Furthermore, the relatively difficult short-term matching task in Experiment 2 would have encouraged participants to rely primarily on perceptual rather than semantic or name representations to mediate their responses. In addition, participants in Experiment 2 did not name the stimuli and were not instructed to attend to their identity.

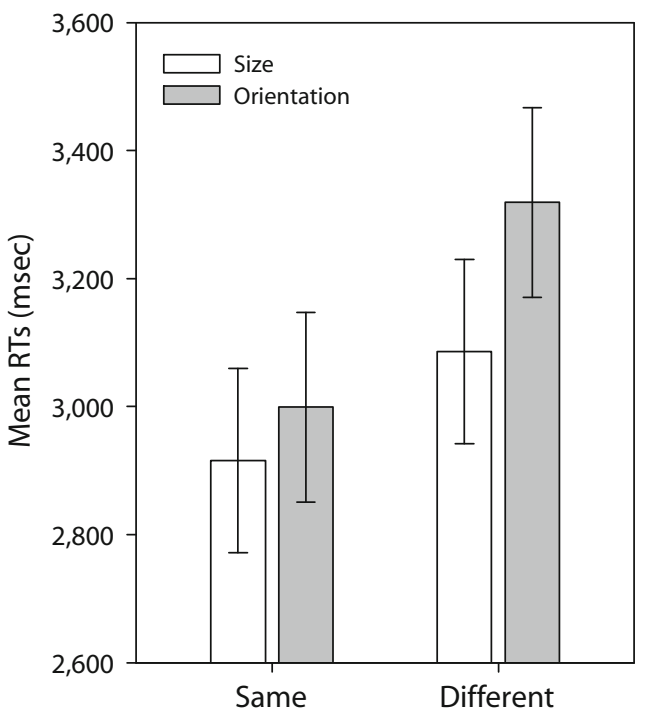

The cost of ignoring size changes in Experiment 2 was comparable to the cost of ignoring a $90^{\circ}$ orientation change in depth that was observed by Lawson (in press) using the same haptic sequential matching task and the larger versions of the same stimuli. Size changes larger than those tested here would probably produce greater effects on performance. However, for very small or large objects, it would be difficult to disentangle the costs arising from size changes per se from any effects due to alterations in the speed and nature of haptic exploration.

\section{GENERAL DISCUSSION}

In Experiment 1, we demonstrated that size and shape changes impaired haptic old/new object recognition for real, everyday objects, extending Srinivas et al.'s (1997) findings for novel, 2-D line patterns. We also found similar costs in visual old/new object recognition, consistent with previous findings of a cost of size changes in vision (Biederman \& Cooper, 1992; Cooper et al., 1992; Fiser \& Biederman, 1995; Uttl et al., 2007). In Experiment 2, we showed that size changes also impaired performance on a short-term haptic matching task with 3-D models of familiar objects, providing further evidence that haptic object representations are size-sensitive. The stimuli in Experiment 2 were better controlled than those in Experiment 1: Only shape information was available, the magnitude of the size change was constant, and the direction of the size change (smaller or larger) was counterbalanced within the study. Although there was a modest cost to both RTs and errors for generalizing over size changes, participants were usually able to match different-sized exemplars of the same-shaped object.

Experiment 1 demonstrated a cost to visual object recognition of physical as opposed to retinal changes in

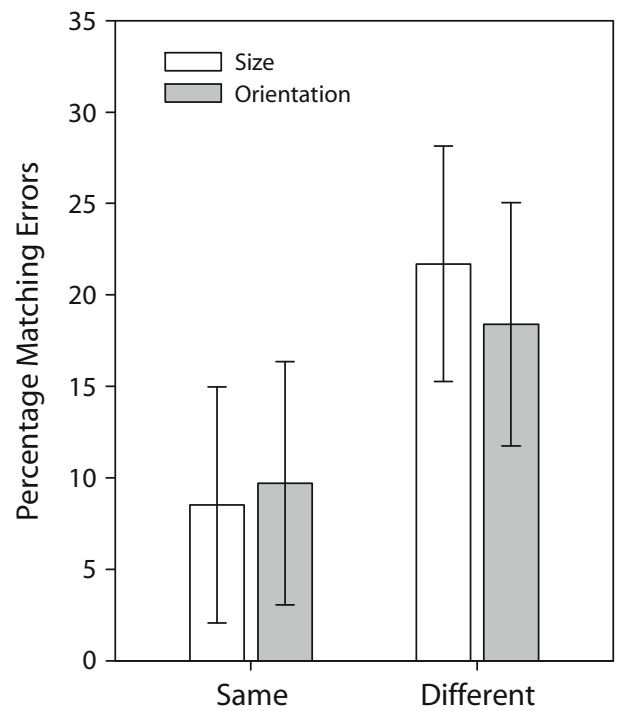

Figure 5. Mean response times (RTs, in milliseconds) and percentage matching errors on same-size and different-size match trials in Experiment 2 (white bars) and same-orientation and different-orientation match trials in Experiment 2 of Lawson (in press; gray bars). Error bars depict $95 \%$ within-participants confidence intervals (Loftus \& Masson, 1994). 
object size. The former may only result from physical differences between objects; the latter may result from altering the distance between the observer and the object. Our results are consistent with those reported by Milliken and Jolicœur (1992), who found that size-change effects in recognition memory for novel shapes were determined by apparent physical size rather than retinal size. Some previous research has presented photographs of real, familiar objects (e.g., Fiser \& Biederman, 1995; Uttl et al., 2007). However, the objects in those studies were depicted in isolation against a blank background, and thus with no indication of the objects' physical size. The visual system could therefore have interpreted size changes in these experiments as being due to either physical size changes or distance changes. The present findings extend these results to real, familiar objects photographed within a standard environmental context. The stimuli unambiguously showed objects at different physical sizes with size cues similar to those found in everyday object recognition. The effects of physical size changes on visual object recognition remain to be tested with 3-D objects in a real environmental context. Generalizing over visual size changes might be more efficient under these conditions, since richer and more consistent depth information would be available. This is an important topic for future research, but the present evidence suggests that the visual recognition of real, 3-D objects in a spatially well-specified scene will still be disrupted by size changes.

In the introduction, we discussed several reasons why size changes might be expected to disrupt haptic recognition more than visual recognition. However, the results of Experiment 1 indicate that size changes disrupt performance similarly in both modalities. This suggests that both modalities may use similar representational strategies to generalize recognition across different-sized exemplars. Perceptual object representations in both modalities seem to retain size information, but transformation of differentsized inputs is quite efficient for both haptics and vision.

We have previously demonstrated that broadly similar costs of generalizing across orientation changes in depth exist in haptic and visual object recognition (Craddock \& Lawson, 2008; Lawson, in press). Experiment 2 revealed that haptic size-change costs are of the same order of magnitude as haptic orientation-change costs. Furthermore, Lawson (in press) found evidence for good crossmodal, size-invariant transfer of information. She found that scale models of objects could be identified haptically, even for objects that were only visually, not haptically, familiar (e.g., a shark or ship).

However, Lawson (in press) also reported evidence that the causes of orientation sensitivity may differ for haptic versus visual object recognition. As the difficulty of discriminating between different objects on mismatch trials increased, visual recognition became increasingly orientation sensitive, whereas the orientation sensitivity of haptic recognition was unaffected. Furthermore, crossmodal visualto-haptic matching was orientation sensitive, whereas haptic-to-visual matching was orientation invariant. Thus, although haptic and visual object recognition were superficially similar, since both exhibited modest orientation sensitivity, the effects of orientation changes were partly dependent on the modality of stimulus presentation and the difficulty of discrimination. This more fine-grained analysis suggests that orientation-sensitive effects may reflect different causes in vision and in haptics. Although here we found similar costs of size changes for haptics and vision in Experiment 1, further research is needed, in which additional factors are manipulated, before stronger conclusions can be drawn about the relative abilities of the haptic and visual systems to ignore size changes.

Overall, for size as for orientation, haptic performance at recognizing objects appears surprisingly similar to visual performance at the same task, given the profound differences in acquiring information between the two modalities. Both modalities show broadly comparable costs in generalizing over size and orientation changes and excellent crossmodal transfer of information. This evidence is compatible with an account of object recognition in which the two modalities share, to some extent, the same processes and representations. In particular, we did not find support for the hypothesis that haptics would involve a much greater cost for generalizing over size changes than does vision because of the relatively greater accessibility and reliability of size information, as compared with other cues, in haptics. However, the important differences between the modalities observed in previous detailed comparisons of the effects of orientation changes on haptic versus visual object recognition (see Lawson, in press) suggest that modality-specific effects may yet emerge when investigating the consequences of coping with haptic versus visual size changes.

\section{AUTHOR NOTE}

This research was supported by an Engineering and Physical Sciences Research Council DTA studentship to the first author and by Fellowship RES-000-27-0162 from the Economic and Social Research Council to the second author. Correspondence related to this article may be sent to M. Craddock, School of Psychology, University of Liverpool, Eleanor Rathbone Building, Bedford Street South, Liverpool L69 7ZA, England (e-mail: m.craddock@liv.ac.uk).

\section{REFERENCES}

Amedi, A., Jacobson, G., Hendler, T., Malach, R., \& Zohary, E. (2002). Convergence of visual and tactile shape processing in the human lateral occipital complex. Cerebral Cortex, 12, 1202-1212. doi:10.1093/cercor/12.11.1202

Amedi, A., Malach, R., Hendler, T., Peled, S., \& Zohary, E. (2001). Visuo-haptic object-related activation in the ventral visual pathway. Nature Neuroscience, 4, 324-330. doi:10.1038/85201

Amedi, A., von Kriegstein, K., van Atteveldt, N. M., Beauchamp, M. S., \& NAumer, M. J. (2005). Functional imaging of human crossmodal identification and object recognition. Experimental Brain Research, 166, 559-571. doi:10.1007/s00221-005-2396-5

Barac-Cikoja, D., \& Turvey, M. T. (1995). Does perceived size depend on perceived distance? An argument from extended haptic perception. Perception \& Psychophysics, 57, 216-224.

Bennett, D. J., \& Warren, W. (2002). Size scaling: Retinal or environmental frame of reference? Perception \& Psychophysics, 64, 462-477.

Berryman, L. J., YaU, J. M., \& Hsiao, S. S. (2006). Representation of object size in the somatosensory system. Journal of Neurophysiology, 96, 27-39. doi:10.1152/jn.01190.2005

Biederman, I., \& Cooper, E. E. (1992). Size invariance in visual object priming. Journal of Experimental Psychology: Human Perception \& Performance, 18, 121-133. doi:10.1037/0096-1523.18.1.121 
Cohen, J. D., MacWhinney, B., Flatt, M., \& Provost, J. (1993). PsyScope: An interactive graphic system for designing and controlling experiments in the psychology laboratory using Macintosh computers. Behavior Research Methods, Instruments, \& Computers, 25, 257-271.

Cooke, T., Jäkel, F., Wallraven, C., \& Bülthoff, H. H. (2007). Multimodal similarity and categorization of novel, threedimensional objects. Neuropsychologia, 45, 484-495. doi:10.1016/j .neuropsychologia.2006.02.009

Cooper, L. A., Schacter, D. L., Ballesteros, S., \& Moore, C. (1992). Priming and recognition of transformed three-dimensional objects: Effects of size and reflection. Journal of Experimental Psychology: Learning, Memory, \& Cognition, 18, 43-57. doi:10.1037/0278 $-7393.18 .1 .43$

Craddock, M., \& Lawson, R. (2008). Repetition priming and the haptic recognition of familiar and unfamiliar objects. Perception \& Psychophysics, 70, 1350-1365. doi:10.3758/PP.70.7.1350

Craddock, M., \& Lawson, R. (in press). Do left and right matter for haptic recognition of familiar objects? Perception.

Deibert, E., Kraut, M., Kremen, S., \& Hart, J., Jr. (1999). Neural pathways in tactile object recognition. Neurology, 52, 1413-1417.

Ernst, M. O., \& BanKs, M. S. (2002). Humans integrate visual and haptic information in a statistically optimal fashion. Nature, 415, 429433. doi: $10.1038 / 415429$ a

Fiser, J., \& Biederman, I. (1995). Size invariance in visual object priming of gray-scale images. Perception, 24, 741-748. doi:10.1068/p240741

GePshtein, S., \& BANKS, M. S. (2003). Viewing geometry determines how vision and haptics combine in size perception. Current Biology, 13, 483-488. doi:10.1016/S0960-9822(03)00133-7

GoldFARB, L., \& Tzelgov, J. (2005). Is size perception based on monocular distance cues computed automatically? Psychonomic Bulletin \& Review, 12, 751-754

Haber, R. N., \& LeVIN, C. A. (2001). The independence of size perception and distance perception. Perception \& Psychophysics, 63, 1140-1152.

James, T. W., Humphrey, G. K., Gati, J. S., Menon, R. S., \& Goodale, M. A. (2002). Differential effects of viewpoint on object-driven activation in dorsal and ventral streams. Neuron, 35, 793-801. doi:10.1016/ S0896-6273(02)00803-6

James, T. W., Humphrey, G. K., Gati, J. S., Servos, P., Menon, R. S., \& Goodale, M. A. (2002). Haptic study of three-dimensional objects activates extrastriate visual areas. Neuropsychologia, 40, 1706-1714. doi:10.1016/S0028-3932(02)00017-9

JAMES, T. W., KIM, S., \& Fisher, J. S. (2007). The neural basis of haptic object processing. Canadian Journal of Experimental Psychology, 61, 219-229. doi:10.1037/cjep2007023

JoliCGeUR, P. (1987). A size-congruency effect in memory for visual shape. Memory \& Cognition, 15, 531-543.

Kiphart, M. J., Hughes, J. L., Simmons, J. P., \& Cross, H. A. (1992). Short-term haptic memory for complex objects. Bulletin of the Psychonomic Society, 30, 212-214.

Klatzky, R. L., Lederman, S. J., \& Reed, C. (1987). There's more to touch than meets the eye: The salience of object attributes for haptics with and without vision. Journal of Experimental Psychology: General, 116, 356-369. doi:10.1037/0096-3445.116.4.356

Klatzky, R. L., LoOmis, J. M., Lederman, S. J., WaKe, H., \& Fujita, N. (1993). Haptic identification of objects and their depictions. Perception \& Psychophysics, 54, 170-178.

Lacey, S., Peters, A., \& Sathian, K. (2007). Cross-modal object recognition is viewpoint-independent. PLOS ONE, 2, e890. doi:10.1371/ journal.pone.0000890

LAWSON, R. (2008). Haptic object recognition: Effects of removing depth cues and restricting exploration. Manuscript in preparation.

LAWSON, R. (in press). A comparison of the effects of depth rotation on visual and haptic 3D object recognition. Journal of Experimental Psychology: Human Perception \& Performance.

Lawson, R., \& Bertamini, M. (2006). Errors in judging information about reflections in mirrors. Perception, 35, 1265-1288. doi:10.1068/ p5498

Lawson, R., Bertamini, M., \& LiU, D. (2007). Overestimation of the projected size of objects on the surface of mirrors and windows. Journal of Experimental Psychology: Human Perception \& Performance, 33, 1027-1044. doi:10.1037/0096-1523.33.5.1027
Lederman, S. J., \& Klatzky, R. L. (1987). Hand movements: A window into haptic object recognition. Cognitive Psychology, 19, 342-368. doi:10.1016/0010-0285(87)90008-9

Lederman, S. J., \& KlatzKy, R. L. (1990). Haptic classification of common objects: Knowledge-driven exploration. Cognitive Psychology, 22, 421-459. doi:10.1016/0010-0285(90)90009-S

Lederman, S. J., \& KLATZKY, R. L. (2004). Multisensory texture perception. In G. A. Calvert, C. Spence, \& B. E. Stein (Eds.), The handbook of multisensory processes (pp. 107-122). Cambridge, MA: MIT Press.

Lederman, S. J., Summers, C., \& Klatzky, R. L. (1996). Cognitive salience of haptic object properties: Role of modality-encoding bias. Perception, 25, 983-998.

Lederman, S. J., Thorne, G., \& Jones, B. (1986). Perception of texture by vision and touch: Multidimensionality and intersensory integration. Journal of Experimental Psychology: Human Perception \& Performance, 12, 169-180.

Loftus, G. R. \& Masson, M. E. J. (1994). Using confidence intervals in within-subject designs. Psychonomic Bulletin \& Review, 1, 476-490.

Loomis, J. M., KlatzKy, R. L., \& Lederman, S. J. (1991). Similarity of tactual and visual picture recognition with limited field of view. Perception, 20, 167-177.

Milliken, B., \& Joliceur, P. (1992). Size effects in visual recognition memory are determined by perceived size. Memory \& Cognition, 20 , 83-95.

Miquée, A., Xerri, C., Rainville, C., Anton, J. L., Nazarian, B., Roth, M., \& Zennou-Azogui, Y. (2008). Neuronal substrates of haptic shape encoding and matching: A functional magnetic resonance imaging study. Neuroscience, 152, 29-39. doi:10.1016/j .neuroscience.2007.12.021

Murray, S. O., Boyaci, H., \& Kersten, D. (2006). The representation of perceived angular size in human primary visual cortex. Nature Neuroscience, 9, 429-434. doi:10.1038/nn1641

Newell, F. N., Ernst, M. O., Tuan, B. S., \& Bülthoff, H. H. (2001). Viewpoint dependence in visual and haptic object recognition. Psychological Science, 12, 37-42. doi:10.1111/1467-9280.00307

Norman, J. F., Clayton, A. M., Norman, H. F., \& Crabtree, C. E. (2008). Learning to perceive differences in solid shape through vision and touch. Perception, 37, 185-196. doi:10.1068/p5679

Reed, C. L., Lederman, S. J., \& Klatzky, R. L. (1990). Haptic integration of planar size with hardness, texture, and planar contour. Canadian Journal of Psychology, 44, 522-545.

Rock, I., \& Victor, J. (1964). Vision and touch: An experimentally created conflict between the two senses. Science, 143, 594-596. doi:10.1126/science.143.3606.594

Sathian, K., \& Lacey, S. (2007). Journeying beyond classical somatosensory cortex. Canadian Journal of Experimental Psychology, 61, 254-264. doi:10.1037/cjep2007026

Srinivas, K., Greene, A. J., \& Easton, R. D. (1997). Visual and tactile memory for 2-D patterns: Effects of changes in size and left-right orientation. Psychonomic Bulletin \& Review, 4, 535-540.

Taylor-Clarke, M., Jacobsen, P., \& Haggard, P. (2004). Keeping the world a constant size: Object constancy in human touch. Nature Neuroscience, 7, 219-220. doi:10.1038/nn1199

Uttu, B., Graf, P., \& Siegenthaler, A. L. (2007). Influence of object size on baseline identification, priming, and explicit memory. Scandinavian Journal of Psychology, 48, 281-288. doi:10.1111/j.1467 $-9450.2007 .00571 \times$

Vuilleumier, P., Henson, R. N., Driver, J., \& Dolan, R. J. (2002). Multiple levels of visual object constancy revealed by event-related fMRI of repetition priming. Nature Neuroscience, 5, 491-499. doi: $10.1038 / \mathrm{nn} 839$

Westwood, D. A., \& Goodale, M. A. (2003). A haptic size-contrast illusion affects size perception but not grasping. Experimental Brain Research, 153, 253-259. doi:10.1007/s00221-003-1599-x

Zhang, M., Weisser, V. D., Stilla, R., Prather, S. C., \& Sathian, K. (2004). Multisensory cortical processing of object shape and its relation to mental imagery. Cognitive, Affective, \& Behavioral Neuroscience, 4, 251-259.

Zuidhoek, S., Kappers, A. M. L., van der Lubbe, R. H. J., \& Postma, A. (2003). Delay improves performance on a haptic spatial matching task. Experimental Brain Research, 149, 320-330. doi:10.1007/s00221-002-1365-5 
APPENDIXA

Results of Visual Rating by Items $(1=$ Low, $7=$ High Typicality or Similarity to Standard $)$

\begin{tabular}{|c|c|c|c|c|c|c|}
\hline \multirow[b]{2}{*}{$\begin{array}{c}\text { Object Name } \\
\text { (Alternative Name) }\end{array}$} & \multicolumn{3}{|c|}{ Typicality Ratings } & \multicolumn{2}{|c|}{$\begin{array}{l}\text { Similarity to } \\
\text { Standard }\end{array}$} & \multirow{2}{*}{$\begin{array}{c}\text { Different } \\
\text { Size Rated } \\
\text { More } \\
\text { Similar }(\%)\end{array}$} \\
\hline & Standard & $\begin{array}{l}\text { Different } \\
\text { Size }\end{array}$ & $\begin{array}{l}\text { Different } \\
\text { Shape }\end{array}$ & $\begin{array}{l}\text { Different } \\
\text { Size }\end{array}$ & $\begin{array}{l}\text { Different } \\
\text { Shape }\end{array}$ & \\
\hline Battery & 4.58 & 5.63 & 4.83 & 4.5 & 2.7 & 60 \\
\hline Bolt (screw) & 2.67 & 3.33 & 1.67 & 5.1 & 5.3 & 70 \\
\hline Book & 6.08 & 5.71 & 5.46 & 5.8 & 5.3 & 90 \\
\hline Bulldog clip & 4.79 & 4.38 & 4.04 & 6.1 & 2.3 & 100 \\
\hline Can & 6.42 & 4.79 & 4.08 & 4.0 & 4.6 & 50 \\
\hline Candle & 5.13 & 4.75 & 4.75 & 3.7 & 1.5 & 70 \\
\hline Comb & 5.13 & 5.75 & 4.92 & 4.8 & 5.2 & 40 \\
\hline Food container (box) & 5.50 & 6.00 & 4.54 & 4.0 & 4.2 & 70 \\
\hline Funnel & 5.58 & 5.58 & 3.08 & 5.1 & 4.2 & 100 \\
\hline Glass bottle & 5.50 & 4.75 & 4.46 & 4.3 & 3.0 & 90 \\
\hline Grater & 4.17 & 3.13 & 5.21 & 4.8 & 3.7 & 70 \\
\hline Hammer & 5.88 & 4.13 & 5.79 & 4.0 & 4.2 & 40 \\
\hline Hole punch & 5.38 & 4.83 & 5.71 & 2.7 & 5.2 & 0 \\
\hline Key & 5.38 & 4.38 & 4.17 & 4.6 & 4.9 & 80 \\
\hline Lid & 4.71 & 5.17 & 4.92 & 5.2 & 4.8 & 80 \\
\hline Lightbulb & 6.00 & 6.00 & 3.67 & 5.2 & 2.9 & 100 \\
\hline Measuring jug & 4.83 & 6.00 & 5.29 & 4.3 & 3.9 & 80 \\
\hline Milk bottle & 5.38 & 5.17 & 4.42 & 4.0 & 3.6 & 80 \\
\hline Mug (cup) & 5.83 & 5.29 & 5.00 & 4.6 & 3.7 & 90 \\
\hline Padlock (lock) & 4.21 & 5.79 & 4.33 & 4.1 & 2.5 & 100 \\
\hline Paintbrush & 5.46 & 4.63 & 2.67 & 2.1 & 4.1 & 20 \\
\hline Pen & 5.88 & 3.58 & 5.83 & 4.8 & 3.9 & 90 \\
\hline Plant pot & 4.88 & 4.88 & 4.88 & 5.1 & 5.4 & 40 \\
\hline Ruler & 5.96 & 5.63 & 4.71 & 5.9 & 5.5 & 60 \\
\hline Scissors & 6.33 & 5.75 & 5.04 & 6.7 & 3.3 & 90 \\
\hline Screwdriver & 5.29 & 5.08 & 5.46 & 5.4 & 4.6 & 80 \\
\hline Sieve & 5.54 & 4.88 & 5.83 & 5.1 & 4.2 & 90 \\
\hline Spanner (wrench) & 5.88 & 4.71 & 4.75 & 5.3 & 4.4 & 100 \\
\hline Spoon & 5.75 & 5.50 & 5.38 & 5.1 & 5.0 & 20 \\
\hline Stapler & 5.75 & 2.50 & 5.88 & 2.0 & 4.1 & 0 \\
\hline Tape measure & 6.00 & 4.75 & 5.79 & 5.5 & 5.8 & 30 \\
\hline Tin & 4.17 & 4.54 & 5.63 & 5.3 & 4.7 & 60 \\
\hline Toothbrush & 4.88 & 5.33 & 6.04 & 4.8 & 3.8 & 70 \\
\hline Torch & 5.38 & 5.54 & 4.33 & 5.0 & 4.8 & 70 \\
\hline Whisk & 5.96 & 5.46 & 5.46 & 5.9 & 5.5 & 30 \\
\hline Wine glass & 5.29 & 4.29 & 5.75 & 3.0 & 2.7 & 60 \\
\hline Mean & 5.32 & 4.93 & 4.83 & 4.7 & 4.2 & 66 \\
\hline
\end{tabular}

Appendix B

Names and Accepted Alternative Names of the New Objects Presented in Experiment 1

\begin{tabular}{lllll}
\hline Alarm clock & Dustpan & Jar & Pliers & Teapot \\
Calculator & Electric plug & Kettle & Razor & Tin opener \\
Camera & Fork & Knife & Salt cellar (salt shaker) & Toothpaste tube (glue) \\
Cassette tape & Glasses (sunglasses) & Ladle & Shoe (trainer) & Tweezers \\
Corkscrew & Hairbrush (brush) & Placemat & Tap & Whistle \\
\hline
\end{tabular}

(Manuscript received September 2, 2008;

revision accepted for publication December 22, 2008.) 